Article

\title{
Assessment of COVID-19 Lockdown Impact on the Air Quality in Eastern Spain: PM and BTX in Urban, Suburban and Rural Sites Exposed to Different Emissions
}

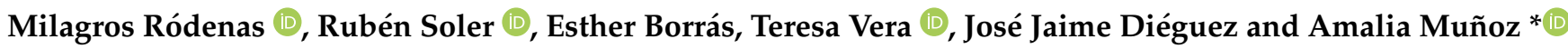

Citation: Ródenas, M.; Soler, R.; Borrás, E.; Vera, T.; Diéguez, J.J.;

Muñoz, A. Assessment of COVID-19

Lockdown Impact on the Air Quality in Eastern Spain: PM and BTX in Urban, Suburban and Rural Sites Exposed to Different Emissions. Atmosphere 2022, 13, 97. https:// doi.org/10.3390/atmos13010097 Academic Editors: Ruixiong Zhang, Tzung May Fu, Deborah S. Gross and Andrey Khlystov

Received: 21 December 2021

Accepted: 1 January 2022

Published: 8 January 2022

Publisher's Note: MDPI stays neutral with regard to jurisdictional claims in published maps and institutional affiliations.

Copyright: (c) 2022 by the authors. Licensee MDPI, Basel, Switzerland. This article is an open access article distributed under the terms and conditions of the Creative Commons Attribution (CC BY) license (https:/ / creativecommons.org/licenses/by/ $4.0 /)$.
EUPHORE Laboratories, Fundación Centro de Estudios Ambientales del Mediterráneo (CEAM), Avda. Charles R. Darwin, 14, Parque Tecnológico, 46980 Paterna, Spain; mila@ceam.es (M.R.); ruben@ceam.es (R.S.); esther@ceam.es (E.B.); teresa@ceam.es (T.V.); jjaime@ceam.es (J.J.D.)

* Correspondence: amalia@ceam.es; Tel.: +34-609644051

\begin{abstract}
In early 2020, the COVID-19 pandemic spread globally, and severe measures to control it were implemented. This study investigates the impact of the lockdown on the air quality of three provinces in the Valencia region, eastern Spain, in the years 2015-2020, focusing on particulate matter (PM). A thorough statistical analysis using different approaches is conducted. Hourly patterns are also assessed. In addition, the role of meteorological parameters on PM is explored. The results indicate an overall $\mathrm{PM}_{10}$ reduction of $16.5 \%$ when comparing the lockdown in 2020 and the 2015-2019 period, while $\mathrm{PM}_{2.5}$ increased by $3.1 \%$. As expected, urban zones experienced higher reductions than suburban zones, which experienced a PM concentration increase. The impact of the drastic drops of benzene, toluene and xylene $(77.4 \%, 58.0 \%$ and $61.8 \%$, respectively) on the PM values observed in urban sites is discussed. Our study provides insights on the effect of activity changes over a wide region covering a variety of air quality stations, urban, suburban and rural, and different emission types. The results of this work are a valuable reference and suggest the need for considering different factors when establishing scientific air pollution control strategies.
\end{abstract}

Keywords: COVID-19; $\mathrm{PM}_{2.5} ; \mathrm{PM}_{10}$; BTX; cluster analysis; meteorology; AQC; air quality

\section{Introduction}

Negative effects of atmospheric particulate matter $(\mathrm{PM})$ pollution on health have been assessed in a large number of studies. Typically, $\mathrm{PM}_{10}$ and/or $\mathrm{PM}_{2.5}$ (PM finer than 10 and $2.5 \mu \mathrm{m}$, respectively) data are used in epidemiological studies to evaluate the effect of the PM pollution on human health. PM causes respiratory and pulmonary diseases $[1,2]$ and also affects the cardiovascular system [3,4].

Despite successful legislation implemented in Europe to reduce air pollutants emissions, the World Health Organization (WHO) [5] estimated that the exposure to $\mathrm{PM}_{2.5}$ particles caused nearly seven million people deaths, mainly related to respiratory system illnesses. Urban population was exposed to high levels of $\mathrm{PM}_{10}$ in 2018 [6]: 15\% above EU standards and $48 \%$ above $\mathrm{WHO}$ air quality guideline value. Equally, the urban population exposure to $\mathrm{PM}_{2.5}$ concentrations above standards were $4 \%$ and $74 \%$, respectively.

The sources of particulate matter are very varied, and their relevance depends on the environment. According to their origin, they can be distinguished between anthropogenic: road traffic, industrial activities, biomass burning and domestic heating, and natural: resuspension and transport of by wind, volcanic eruptions, seismic activity, specific events such as Saharan dust intrusions, particularly relevant in the western Mediterranean [7,8].

Volatile organic compounds (VOCs) constitute another large group of air pollutants, which include a mixture of hundreds of species with a well-known harmful effect on human health $[9,10]$ and on the environment, due to their implication on the production of secondary pollutants such as tropospheric ozone and secondary organic aerosol [11-13]. 
Among them, benzene, toluene and xylene (BTX) are the most common traffic-related monoaromatic hydrocarbons in urban environments $[14,15]$. The continuous measurement of VOCs is essential to estimate population exposure to hazardous gases and implement effective control strategies.

The COVID-19 pandemic that began at the end of 2019 continues to spread globally today, having so far caused millions of deaths around the world, and the situation remains very serious. Spain was one of the countries hardest hit by the pandemic in the first half of 2020. At the end of March 2020, confirmed SARS-CoV-2 cases in Spain made it the most affected country worldwide. On 11 March 2020, the WHO declared a global pandemic of COVID-19. Following this, on 14 March 2020, the Spanish government, aiming to contain the pandemic spread, announced the implementation of a series of drastic measures. These included a lockdown, traffic restrictions, cancellation of national and international flights and the cease of every nonessential activity. These measures came into force on $15 \mathrm{March}$ for two months, until 17 May, to curb the spread of infection by limiting people's movement, helping to maintain "social distancing". The measures were gradually lifted until activity returned to normal. By this point, the world had 6,234,322 confirmed cases of COVID-19 and 375,541 deaths [16].

The prevention and control measures mentioned above resulted in a diminution of anthropogenic activity and therefore were closely related to the air quality. The unprecedented mobility and economy activity reduction measures implemented in response to COVID-19 posed a unique opportunity to better understand the impact of natural versus anthropogenic causes of air pollution, which will help to draft policies aimed at improving the air quality. Within this framework, a number of studies have explored the impact of lockdown on air quality. Rodriguez-Urrego et al. [17] reported an average $\mathrm{PM}_{2.5}$ decrease of $12.5 \%$ over the 50 most polluted capital cities worldwide, although a discrete reduction of only 5\% was observed in European cities under study versus 22\% on the American continent and $16 \%$ on the Asian continent. Most of the cities experienced a reduction during the COVID-19 lockdown, although a non-negligible figure of 14 out of the 50 cities reported an increase of $\mathrm{PM}_{2.5}$, part of which was attributed to an isolated effect produced by winds or fires. The reason for the results for other cities, such as Paris, with an increase of nearly $30 \%$, was not evident in the study.

Nitrogen dioxide $\left(\mathrm{NO}_{2}\right)$, nitrogen oxide (NO), $\mathrm{PM}_{2.5}$ and $\mathrm{PM}_{10}$ concentrations were reduced in many countries and locales around the world during the COVID-19 lockdown. However, this was not always the case for PM. For instance, in southern and in central China, in situ measurements indicated a decrease of $\mathrm{PM}_{2.5}(10 \%$ to $60 \%)$ [18], while increases were found in the north and east in a study using satellite data and models [19]. In that study, the $\mathrm{PM}_{2.5}$ increase was also attributed to the higher relative humidity and to the increased oxidation capacity of the atmosphere. Zhang et al. [20] and Mao et al. [21] also suggested that complex aerosol chemistry and meteorological influence are the reasons for this PM increase.

Traffic is a major source of primary aerosols. It contributes to the formation of secondary aerosols through the emission of $\mathrm{SO}_{2}, \mathrm{VOCs}$ and $\mathrm{NO}_{\mathrm{x}}$, which are precursors of aerosols. For this reason, the increase in aerosols despite the dramatic limitation in the traffic activity is, to date, not well understood. Reduction in $\mathrm{NO}_{\mathrm{x}}$ emissions is known to result in enhanced ozone concentration due to reduced titration [12]. Shen et al. [22] found similar percentage decreases in urban and background sites in the Po Valley for $\mathrm{NO}_{2}$ and NO (above $41 \%$ and 59\%, respectively). They also found benzene and toluene concentration reductions of 33 and $37 \%$, respectively, while they reported only slight changes in $\mathrm{PM}_{2.5}$ and $\mathrm{PM}_{10}$. Ciarelli et al. [23] observed a mild increase in $\mathrm{PM}_{2.5}$ levels in a modeling study at the same sites investigated in the current study and in Swiss Plateau regions. They indicated that the ozone enhancement increased the overall oxidizing capacity of the atmosphere, i.e., $\mathrm{OH} \cdot$ and $\mathrm{NO}_{3} \cdot$ radicals, which favored SOA formation. This lowered the overall levels of particulate pollution, which suggests that emission sources other than traffic and 
processes have an important impact on particulate number and mass concentration, and should be considered in control pollution strategies.

Sicard et al. [24] found overall reductions in $\mathrm{PM}_{2.5}$ and $\mathrm{PM}_{10}$ of $8 \%$ in urban stations of the European cities studied, which is a much smaller reduction than in Wuhan $(\sim 42 \%)$. The PM reduction due to the traffic and industrial activity limitation was, in part, caused by the PM emissions from indoor activities during lockdown in some cities. Variability in $\mathrm{PM}_{10}$ reduction was observed in [25], which studied 11 cities in Spain, with one AQC from each city, finding significant reductions in Barcelona, Valencia and Sevilla and no significant reduction in the remaining eight cities.

Several approaches have been used to evaluate the effect of lockdown on air quality, typically consisting of statistical studies comparing data from air quality cabins (AQCs) during the lockdown period with (a) the period before [26] and (b) the same period in previous years $[24,27]$. The same methods have been used based on satellite observations rather than AQCs [28]. On the other hand, meteorology has a significant role in controlling PM levels [29]. The processes of formation, removal and dispersion are influenced by meteorological parameters such as temperature, radiation, relative humidity, precipitation, wind speed and direction. This has led to numerous studies exploring this correlation between meteorological variables and the behavior of different pollutants in order to get a better understanding of their effect on climate change [30]. Authors of these studies state that, while meteorology has a clearer correlation with pollutants such as ozone and $\mathrm{NO}_{\mathrm{x}}$, its correlation with PM remains uncertain in many scenarios due to the large variety of PM components. Therefore, the closing of schools, industrial activities and businesses had a clear impact on activity levels and air pollutant emissions and air quality during the lockdown.

The aim of this study is to quantify the effect of the COVID-19 lockdown on air quality (PM and BTX) by considering the reference period of March-May of 2015-2019 using option (b) described in the previous paragraph and assessing the impact of meteorology. The lockdown affected urban sites as well as industrial and rural sites, whose activity was limited by direct legislative restrictions and by a general reduction in the demand of products and the slowdown of the economy. Therefore, and unlike most of the studies based on urban sites, this work has considered a network of AQCs, which includes cabins in different environments: urban, rural, suburban, exposed to traffic, industrial and background emissions. This allows us to compare and discuss the effect of lockdown on the air quality based on the site and type of emission.

\section{Methodology}

\subsection{Data Sources and Study Area}

The Valencia region is the fourth most populous autonomous community in Spain with more than 5 million inhabitants and a surface of nearly $25,000 \mathrm{~km}^{2}$, consisting of 3 provinces: Alicante, Castellón and Valencia. Valencia is the homonymous capital of the region and the third largest metropolitan area in the country, with 1,392,000 inhabitants and an area of nearly $400 \mathrm{~km}^{2}$. It is also the third largest city in Spain with more than 800,000 inhabitants over an area of nearly $135 \mathrm{~km}^{2}$. The region is at the east of the country by the Mediterranean coast, where there is very dense residential housing. Agriculture plays an important role in the economy of the region, but in recent decades there has been growth in the secondary sector with a strong industry, especially in Castellón, and in the tertiary sector; tourism is the region's major industry.

The regional air quality network of the Valencia region comprises 60 air quality stations distributed through the territory of the aforementioned three provinces, with 47 of them measuring $\mathrm{PM}_{10}$ particles and 38 measuring $\mathrm{PM}_{2.5}$. In this study, the effect of lockdown due to COVID-19 on the air quality of the Valencia region was investigated by analyzing fine particulate matter $\left(\mathrm{PM}_{2.5}\right)$, coarse particulate matter $\left(\mathrm{PM}_{10}\right)$ and $\mathrm{BTX}$. Since meteorological conditions affect the dispersion of contaminants and therefore their chemistry and removal [26,31], our study involved comparing data from the lockdown 
period with the same period in the years 2015-2019. The same season is compared to avoid large meteorological variability of winter to spring. Therefore, hourly and daily data from the lockdown period, i.e., from 15 March 2020 to 17 May 2020, were compared against the reference period, consisting of the same period in the years 2015 to 2019, representing the baseline conditions.

Hourly concentrations with $>75 \%$ of validated data were used to calculate aggregated daily values according to legislation. For statistical purposes, 21 AQCs were selected that fulfilled the following criteria: (1) availability of spatial coverage to cover different types of emission sources, location, etc.; (2) at least four years of available data reporting, including 2020; and (3) representativeness of an area and known not to be affected by artificial external sources (e.g., installed in school yards and subject to resuspension of particles). Figure 1 shows the geographical location of the different sampling sites in the western Mediterranean area and Table S1 in the supplementary material summarizes the selected air quality stations used in this study indicating the type of environment (URB = urban, SUB = suburban and RUR = rural), type of emissions (TRA = traffic, IND = industrial, $\mathrm{BK}=$ background) and site (INN = inner, COA = coast). Together with particulate matter, meteorological parameters also collected by the air quality network were used in this study: temperature (TEMP), relative humidity (RH), radiation (RAD), rainfall (PLU), wind speed (WS) and wind direction (WD). Due to their role as precursors of particles, volatile organic compounds (BTX: benzene $=\mathrm{C} 6 \mathrm{H} 6$, toluene $=\mathrm{C} 7 \mathrm{H} 8$ and $x y l e n e=\mathrm{C} 8 \mathrm{H} 10$ ) were also considered.

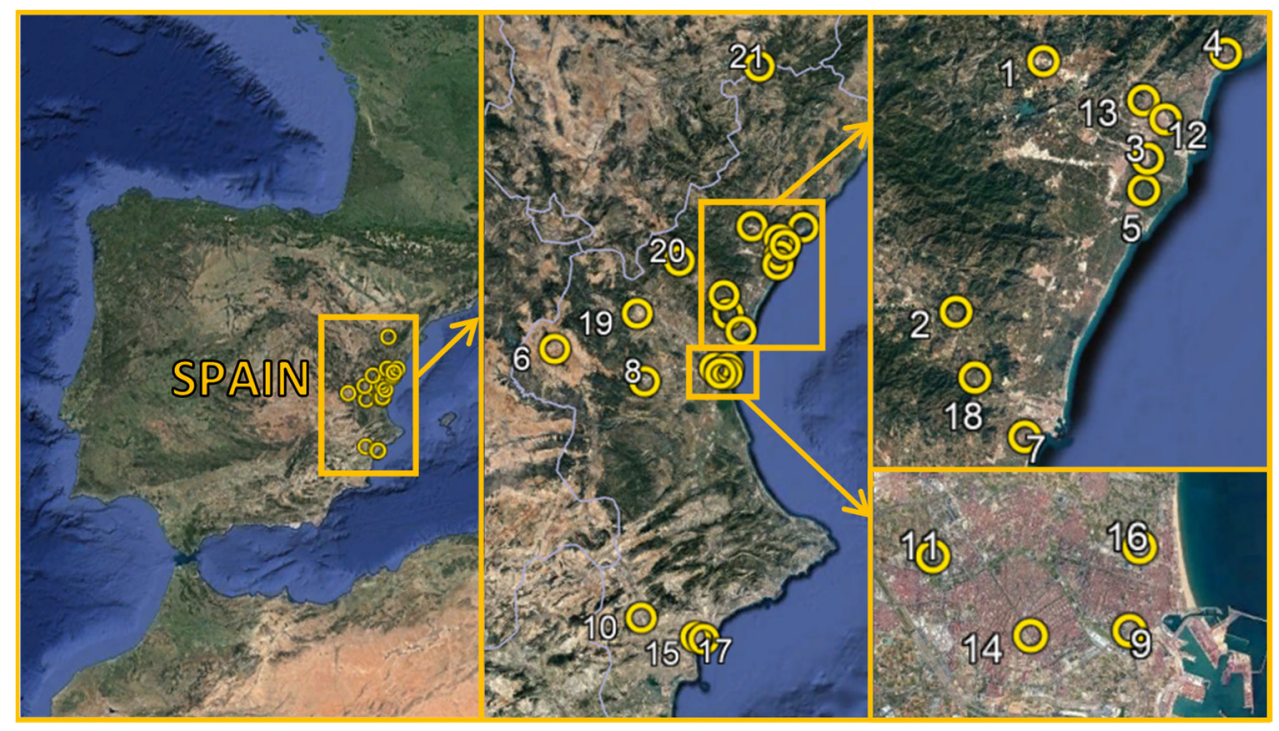

Figure 1. Location of the monitoring air quality stations on the Spanish Mediterranean coast. Map data: (C) 2022 Google. Image Landsat/Copernicus.

\subsection{Saharan Dust Outbreaks Identification}

In order to isolate the effect of the reduction in anthropogenic activity during the lockdown period on aerosol concentrations, days with Saharan dust outbreaks (SDO) during the considered period (2015 to 2020) were removed from the database. The assessment of Saharan dust events that passed through the Mediterranean area during the study period was retrieved from a Spanish governmental database [32]. In this database, the identification of SDOs is carried out using dust forecast models (NAAPS, DREAM and SKIRON). Moreover, a back-trajectory analysis by HYSPLIT model $[33,34]$ is used to confirm the north African origin of the air masses during the SDOs identified. Five-day back-trajectories ending at different points of the study region at 750, 1500 and $2500 \mathrm{~m}$ above ground level (a.g.1.) at 12:00 UTC are also provided for these days. This procedure is based on a methodology for the identification and quantification of the contribution of SDOs in Spain and Portugal [35]. 


\subsection{Statistical Analysis}

Different approaches were used to evaluate the effects of lockdown on airborne PM. An estimation of the changes between the two sets of series considered, the lockdown period in 2020 and the equivalent time period over the 5 previous years, was conducted, comparing the averages of PM concentrations. In addition, the variation of daily mean concentrations expressed as percentages $[24,26]$ was calculated for each day of the year (DoY) according to Equation (1)

$$
\%_{\text {Variation }}=\frac{P M_{\text {lockdown }}-P M_{\text {reference }}}{P M_{\text {reference }}} \cdot 100
$$

where $P M_{\text {lockdown }}$ is the particle concentration in 2020 and $P M_{\text {reference }}$ is the particle concentration in the reference period (2015-2019). The deviation of daily mean concentrations expressed as percentages was also calculated for each day of the year (DoY) within the period under consideration. In order to ensure coherence when comparing both sets of data, given the fact that human activity is generally lower on weekends than on working days, the minimally required shift in days was introduced in the years 2015 to 2019 when comparing baseline data to the days of the same period in 2020. By using this approach, hourly data were also computed to assess the change of pattern between working days and weekends due to the effect of the lockdown.

Box plots were computed to graphically compare the variability of distributions for previous years with that for 2020. These box plots show a median of concentrations as central markers and the edges of the boxes correspond to the 25th and 75th percentiles, also called first quartile $(\mathrm{Q} 1)$ and third quartile $(\mathrm{Q} 3)$, respectively, being the interquartile range, $\mathrm{IQR}=\mathrm{Q} 3-\mathrm{Q} 1$, the length of the box. The lockdown effect was assessed by aggregating data from AQCs according to their typologies, i.e., considering the type of emissions they are exposed to and the type of environment in which they are installed. The latter was assessed by applying agglomerative hierarchical clustering analysis to the concentration data using the Pearson correlation coefficient $(\mathrm{R})$ distance [36]. For a better classification and to consider all the variability among the $\mathrm{AQCs}$, both $\mathrm{PM}_{2.5}$ and $\mathrm{PM}_{10}$ concentrations were used. The average was applied to compute the distance between clusters. The dendrogram, which graphically represents the cluster tree, is shown for easier interpretation [37]. Both box plots and clusters were computed using MATLAB $^{\circledR}$ version 2019a [38,39].

Another question raised in this study is whether meteorological parameters affect PM concentrations. This was examined by calculating the corresponding Pearson's correlation coefficient, R, between the PM concentration profiles and the HR, PLU, RAD, WIND and TEMP patterns. $R$ varies between $-1<\mathrm{R}<+1$, with the signs + and - indicating positive and negative correlations, respectively. The associated $p$-values were also calculated to test the null hypothesis, when there is no relationship between the observed phenomena. P-values range from 0 to 1 , where those close to 0 correspond to a significant correlation in $\mathrm{R}$ and a low probability of observing the null hypothesis. To test for statistical significance between groups, we used the same approach as in ref. [24], and we used the non-parametric Kruskal-Wallis test followed by a post hoc test using Fisher's least significant difference and $p$-values adjusted with the Holm correction. A $p$-value $<0.05$ was considered statistically significant and therefore as indicative of significant correlation.

\section{Results and Discussion}

\subsection{Particulate Concentration Variation}

Average concentrations of particulate matter were calculated as a first step to compare concentrations during the lockdown with those of previous years. The results showed that mean $\mathrm{PM}_{10}$ concentration was lower during the lockdown $\left(9.1 \mu \mathrm{g} \cdot \mathrm{m}^{-3}\right)$ than in the reference period $\left(10.9 \mu \mathrm{g} \cdot \mathrm{m}^{-3}\right)$. Conversely, mean $\mathrm{PM}_{2.5}$ levels were slightly higher during lockdown $\left(6.7 \mu \mathrm{g} \cdot \mathrm{m}^{-3}\right)$ compared to the lockdown reference period $\left(6.5 \mu \mathrm{g} \cdot \mathrm{m}^{-3}\right)$. Figure 2 presents percentage variations of $\mathrm{PM}_{10}$ and $\mathrm{PM}_{2.5}$ for each station. A summary of statistics of $\mathrm{PM}_{10}$ and $\mathrm{PM}_{2.5}$ for each cabin for both reference and lockdown periods can be found 
in Tables S2 and S3 in the supplementary material. A general characterization of $\mathrm{PM}_{10}$, $\mathrm{PM}_{2.5}$ and BTX data sets, grouping all stations in this study, is shown in Table S4 in the supplementary material.

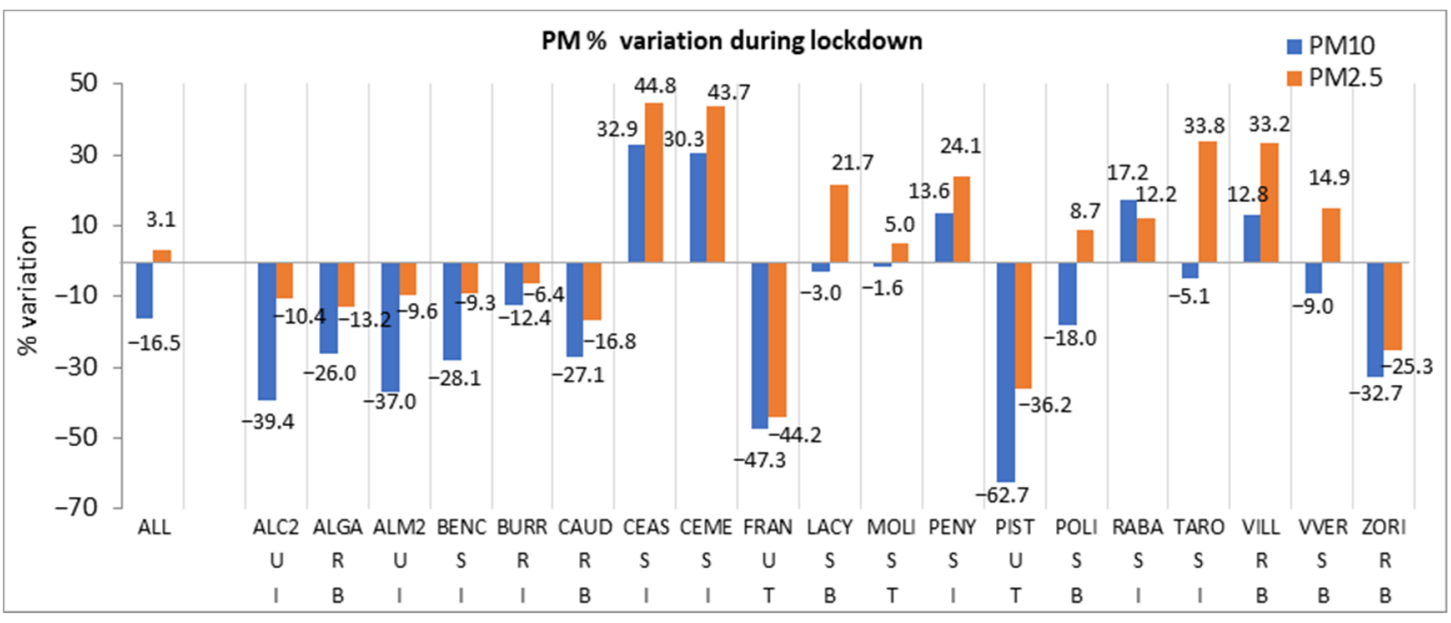

Figure 2. Percentage variation of $\mathrm{PM}_{10}$ and $\mathrm{PM}_{2.5}$ for each station. Codes below ACQ names refer to their type of environment, U: urban, S: suburban, R: rural; and type of environment, T: traffic, I: industrial, B: background.

An overall relative decrease in PM concentration was observed during the lockdown period in 2020. In total, 14 of the 19 AQCs in this study recorded a reduction in $\mathrm{PM}_{10}$, ranging from 1.6 to $62.7 \%$, with an overall reduction of $16.5 \%$. Despite the fact the 9 AQCs experienced reductions varying from 6.4 to $44.2 \%$, an overall increase in $\mathrm{PM}_{2.5}$ of $3.1 \%$ was found. A study limited to several environments in the city of Valencia [40] obtained similar results in two traffic stations common to this work (reductions of $56-53 \%$ and $60-41 \%$ in $\mathrm{PM}_{10}-\mathrm{PM}_{2.5}$ in the FRA and PIST stations, respectively). However, in comparison to our data, different PM percentage variations were found at other two common stations (reductions of 33-30\% and 37-13\% in $\mathrm{PM}_{10}-\mathrm{PM}_{2.5}$ at MOLI and POLI stations, respectively). A detailed review of the data explains that this difference is due to the fact that, unlike our study, Donzelli et al. [40] considered a reference period based only on 2019 data.

Similar values for $\mathrm{PM}_{10}$ (14\% decrease) and $\mathrm{PM}_{2.5}$ (6\% increase) were found in the United Kingdom [41]. The large fluctuation in $\mathrm{PM}_{2.5}$ variations in some European cities during lockdown has been reported in [17]. The largest reductions were found in cabins in urban sites and affected by traffic; in Valencia, reductions of $62.7 \%$ in PIST and $47.3 \%$ in FRAN for $\mathrm{PM}_{10}$ and $36.2 \%$ and $44.2 \%$ for $\mathrm{PM}_{2.5}$ were recorded. Urban AQCs exposed to industrial emissions reported deductions varying from $37.0 \%$ to $39.4 \%$ in $\mathrm{PM}_{10}$, although reductions in $\mathrm{PM}_{2.5}$ were less significant (10\%). This is also observed in the box plots (Figure S1 in the supplementary material), where there is a notable variability in 2015-2019, but not in 2020. Conversely, CEAS and CEME, categorized as SUB and exposed to industrial emissions, presented increases of $32.9 \%$ and $30.3 \%$ for $\mathrm{PM}_{10}$ and $44.8 \%$ and $43.7 \%$ in $\mathrm{PM}_{2.5}$, showing higher ranges of variability and higher medians in 2020.

The variability of the particulate concentrations in the considered time periods along with the median is shown in the box plot in Figure S1a,b. The percentage reductions in $\mathrm{PM}_{10}$ and $\mathrm{PM}_{2.5}$ are supported by Figure S1, where the PM concentrations are presented in box plots, showing a general higher variability in $\mathrm{PM}_{10}$ for the reference than for the lockdown period. Nevertheless, the difference in the median values, $9.0 \mu \mathrm{g} \cdot \mathrm{m}^{-3}$ for the reference and $8.0 \mu \mathrm{g} \cdot \mathrm{m}^{-3}$ for the lockdown period, shows a smaller difference than the $\%$ of variation. Regarding $\mathrm{PM}_{2.5}$, less variability was found in $\mathrm{PM}_{2.5}$ concentrations between both sets of data, being the global median $5.0 \mu \mathrm{g} \cdot \mathrm{m}^{-3}$ in the years 2015 to 2019 and $6.0 \mu \mathrm{g} \cdot \mathrm{m}^{-3}$ in 2020. In general, suburban AQCs recorded an increase in $\mathrm{PM}_{2.5}$ and those which are both suburban and industrial recorded an increase in $\mathrm{PM}_{10}$. 
Figure 3 shows PM percentage variations during lockdown compared to the reference period calculated for the whole study network and the different cabin groups considered using average observed PM concentrations (Table S5 in the supplementary material). According to the classification by type of environment, urban cabins showed the largest decrease in concentrations of both $\mathrm{PM}_{10}$ and $\mathrm{PM}_{2.5}$ during the lockdown period; their average concentrations decreased by $49.0 \%$ and $27.3 \%$, respectively. Taking into account that SDO was removed from the database, these notable decreases in PM concentrations can be explained by the drastic reduction in anthropogenic activity resulting from lockdown. A smaller but equally consistent $\mathrm{PM}_{10}$ concentration reduction (31\%) was found in Barcelona [26].

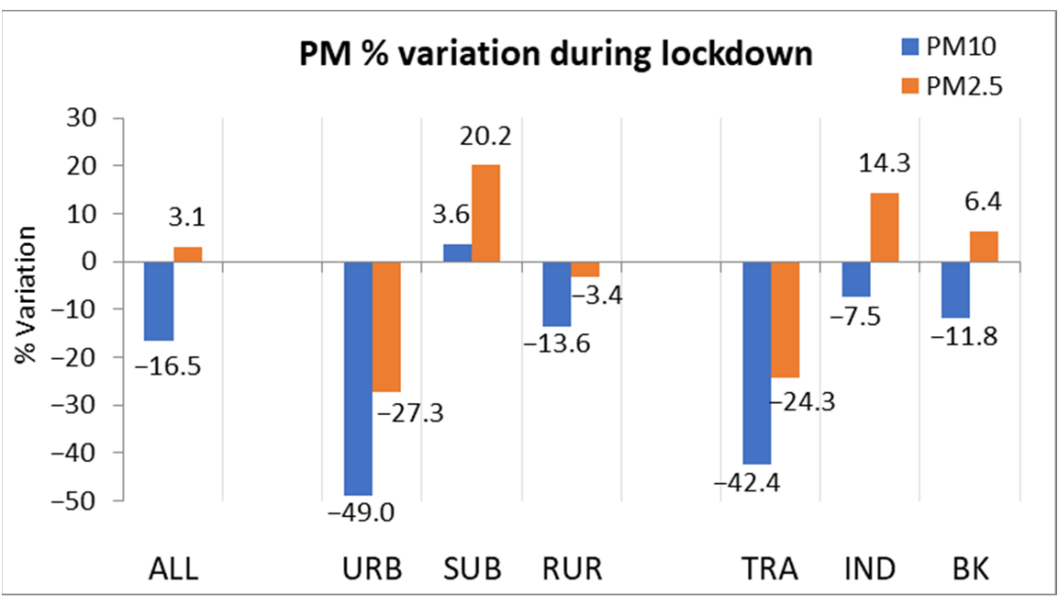

Figure 3. Variation of PM for all the stations and stations grouped according to different characteristics.

$\mathrm{PM}_{10}$ or $\mathrm{PM}_{2.5}$ levels in rural and suburban areas were not as impacted by the COVID-19 lockdown period. Whereas rural stations showed a similar pattern of larger percentage reductions in $\mathrm{PM}_{10}$ concentrations than $\mathrm{PM}_{2.5}$ reductions, with more moderate reductions in average concentration of $13.6 \%$ and $3.5 \%$, respectively, suburban environments experienced the opposite behavior, recording overall percentage increases of $3.6 \%$ and $20.2 \%$ in average $\mathrm{PM}_{10}$ and $\mathrm{PM}_{2.5}$ concentrations during lockdown.

According to the emission type classification (TRA/IND/BK), all cabin groups experienced a decrease in $\mathrm{PM}_{10}$ levels during lockdown. In Figure 3 it can be seen that the traffic stations experienced the steepest decrease in the average concentration of both $\mathrm{PM}_{10}$ and $\mathrm{PM}_{2.5}$, with drops of $42.4 \%$ and $24.3 \%$, respectively. As for urban cabins, these decreases in traffic PM concentrations were due to the limited anthropogenic activities (traffic, works, etc.). A work in 11 metropolises in Spain with a different analysis approach found slightly lower $\mathrm{PM}_{10}$ percentage reductions $(-32 \%$ and $-38 \%$ in the metropolitan and traffic environments, respectively) and similar $\mathrm{PM}_{2.5}$ percentage decreases $(-22 \%$ and $-27 \%$ for the same environments) in Valencia [42]. In ref. [24], very similar percentage decreases in $\mathrm{PM}_{10}$ and $\mathrm{PM}_{2.5}$ results for traffic environments in European cities including Valencia (52.3\% and 29.3\% respectively) during lockdown were recorded. A PM 2.5 decrease of $29 \%$ associated with reduced road traffic during lockdown in South Carolina was reported [27]. Accordingly, Figure 4 shows box plots with medians of $16.4 \mu \mathrm{g} \cdot \mathrm{m}^{-3}$ of $\mathrm{PM}_{10}$ in the reference period versus $8.0 \mu \mathrm{g} \cdot \mathrm{m}^{-3}$ in 2020 in urban AQCs. This is also observed in cabins labelled as traffic (Figure 5), with decreases of $14.0 \mu \mathrm{g} \cdot \mathrm{m}^{-3}$ and $8.0 \mu \mathrm{g} \cdot \mathrm{m}^{-3}$, respectively. To avoid smoothing as a result of calculating averages over the previous years, variability of individual year distributions was plotted, showing that concentration variability of $\mathrm{PM}_{10}$ and $\mathrm{PM}_{2.5}$ for the urban and traffic stations during the lockdown was lower than each reference year (Figures S2 and S3 in the supplementary material), which is more significant in $\mathrm{PM}_{10}$. 


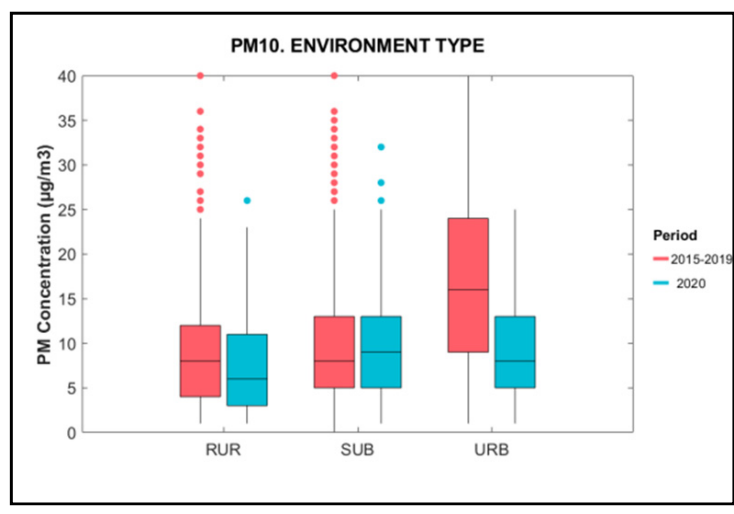

(a)

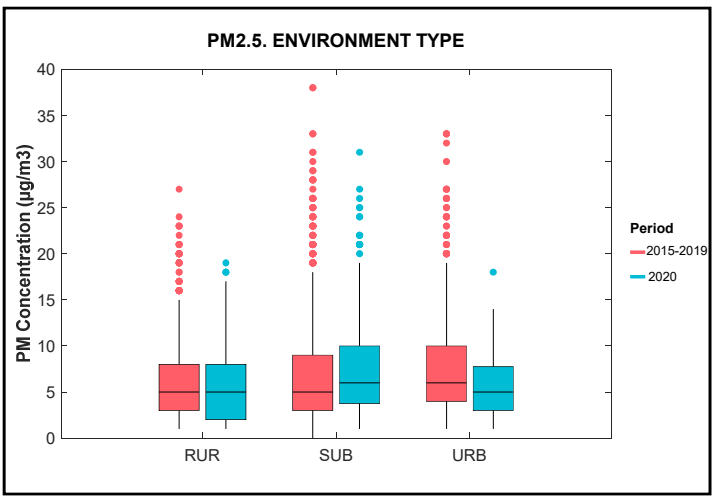

(b)

Figure 4. (a,b) Box plots by environment type. $(\mathbf{a}, \mathbf{b})$ represent $\mathrm{PM}_{10}$ and $\mathrm{PM}_{2.5}$ respectively in the reference and the lockdown periods. The marker inside the boxplot is the median, and lower and upper box boundaries are the 25th $(\mathrm{Q} 1)$ and 75th $(\mathrm{Q} 3)$ percentiles, respectively. Lower and upper whiskers represent Q1 - 1.5·IQR and Q3 + 1.5·IQR, respectively. Dots are outliers.

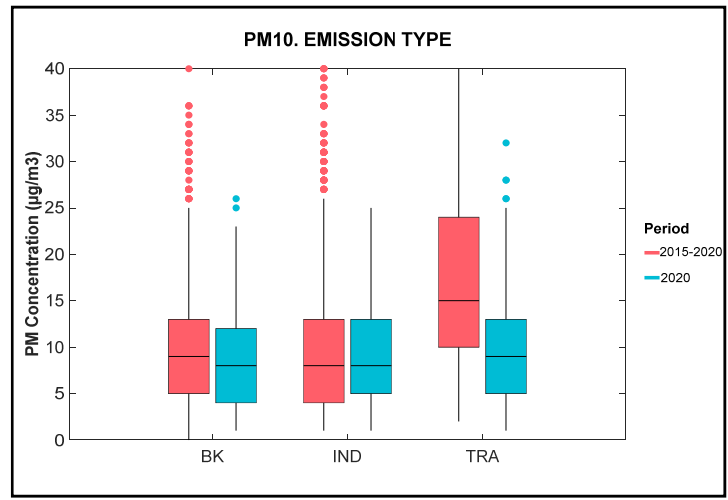

(a)

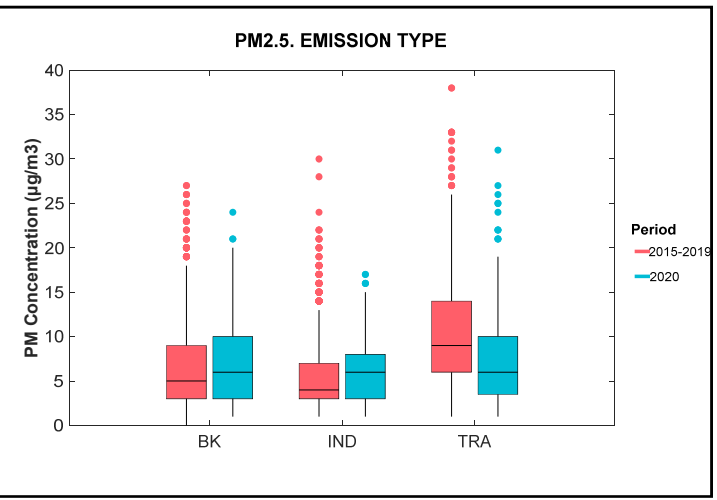

(b)

Figure 5. (a,b) Box plots by emission type. $(\mathbf{a}, \mathbf{b})$ represent $\mathrm{PM}_{10}$ and $\mathrm{PM}_{2.5}$ respectively in the reference and the lockdown periods. The marker inside the boxplot is the median, and lower and upper box boundaries are the 25th (Q1) and 75th (Q3) percentiles, respectively. Lower and upper whiskers represent Q1 - 1.5· IQR and Q3 + 1.5·IQR, respectively. Dots are outliers.

In contrast to the traffic stations, for those classified as IND and $\mathrm{BK}, \mathrm{PM}_{10}$ concentration decreased moderately and $\mathrm{PM}_{2.5}$ levels increased during lockdown, with $\mathrm{PM}_{2.5}$ medians of $4.0 \mu \mathrm{g} \cdot \mathrm{m}^{-3}$ and $5.0 \mu \mathrm{g} \cdot \mathrm{m}^{-3}$ for IND and BK sites, respectively, for $\mathrm{PM}_{2.5}$ in the reference period and $6.0 \mu \mathrm{g} \cdot \mathrm{m}^{-3}$ during the lockdown for both AQC types. Regarding $\mathrm{PM}_{10}$, industrial cabins registered medians of $8.0 \mu \mathrm{g} \cdot \mathrm{m}^{-3}$ in both periods and BK reduced from $9.0 \mu \mathrm{g} \cdot \mathrm{m}^{-3}$ in the reference period to $8.0 \mu \mathrm{g} \cdot \mathrm{m}^{-3}$ in the lockdown, with similar variability in each individual year. $\mathrm{PM}_{10}$ levels at $\mathrm{BK}$ stations were reduced by $11.9 \%$, while, contrary to expectations, levels at industrial stations decreased by only $7.5 \% . \mathrm{PM}_{2.5}$ at IND and BK stations experienced overall increases of $14.3 \%$ and $6.4 \%$, respectively, with small variability and similar medians (Figure 5), and with particle concentrations of industrial stations during lockdown were higher than averages recorded between 2016 and 2018. The lower reduction and even increase of PM in nonurban stations during the lockdown, might be partly due to the formation of particles resulting from the start of agricultural activity at the end of the winter and coinciding with the initiation of the lockdown. The spreading of fertilizers is known to be an important source of ammonium nitrate in European countries, which together with $\mathrm{NO}_{\mathrm{x}}$ emitted by agriculture and industry, contributes to the formation of secondary $\mathrm{PM}_{2.5}$ [43]. Another reason that might have influenced the moderate 
variations of particles is the simultaneous action of activities and sources that did not completely diminish during the lockdown, such as biomass burning and industry, which did not experience a total or synchronized halt in activity. The lack of data on the chemical composition of PM did not allow us to determine the evolution and the actual contribution of PM from each source. Despite the similar medians found and box sizes delimited by percentiles 25th and 75th, concentrations beyond the latter percentile, represented by dots, can be observed in all the subgroups of AQCs in the reference period. This confirms its generally higher variability compared to the lockdown. Box plots of individual years show similar sizes throughout the period 2015-2020, although AQCs grouped as URB and TRA clearly confirm the reduction of $\mathrm{PM}_{10}$ during the lockdown, which is not as significant for $\mathrm{PM}_{2.5}$.

\subsection{Hourly PM Pattern}

Taking into account that the hourly pattern of particles is affected by activities carried out by citizens, the hourly PM profiles have been calculated to observe whether the halt of activity during the lockdown affected such PM patterns. Figure 6 shows an example of urban AQCs, the most prone to be affected by changes in human activity, and distinguishes between working days and weekends. Individual hourly patterns of each of the AQCs are shown in the supplementary material (Figures S4-S7).

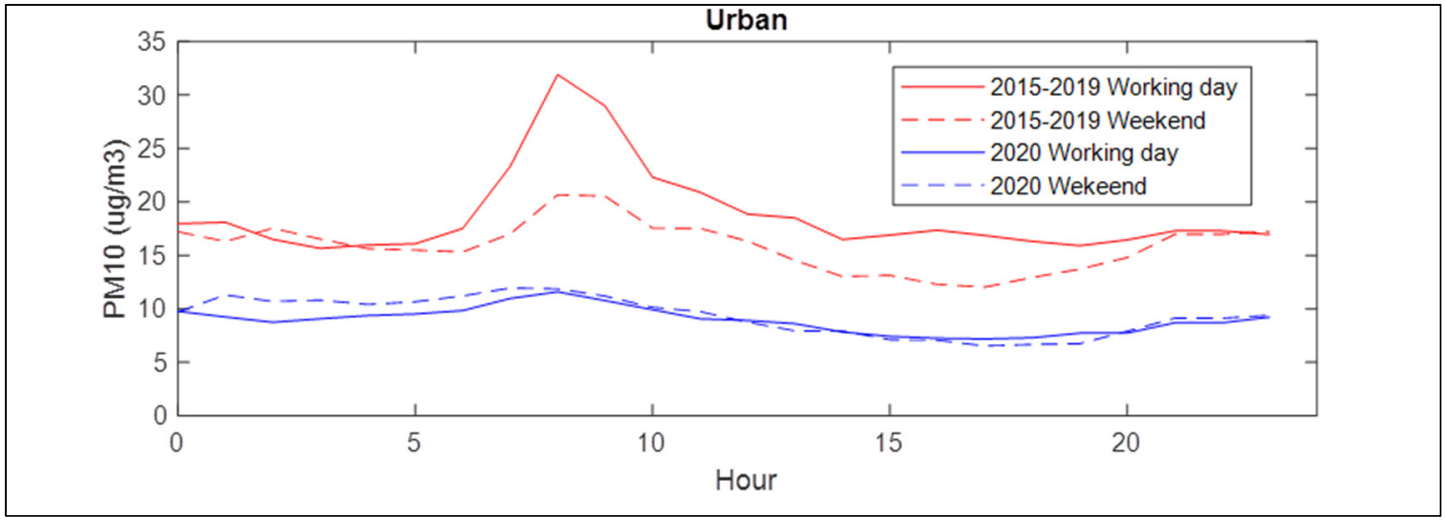

(a)

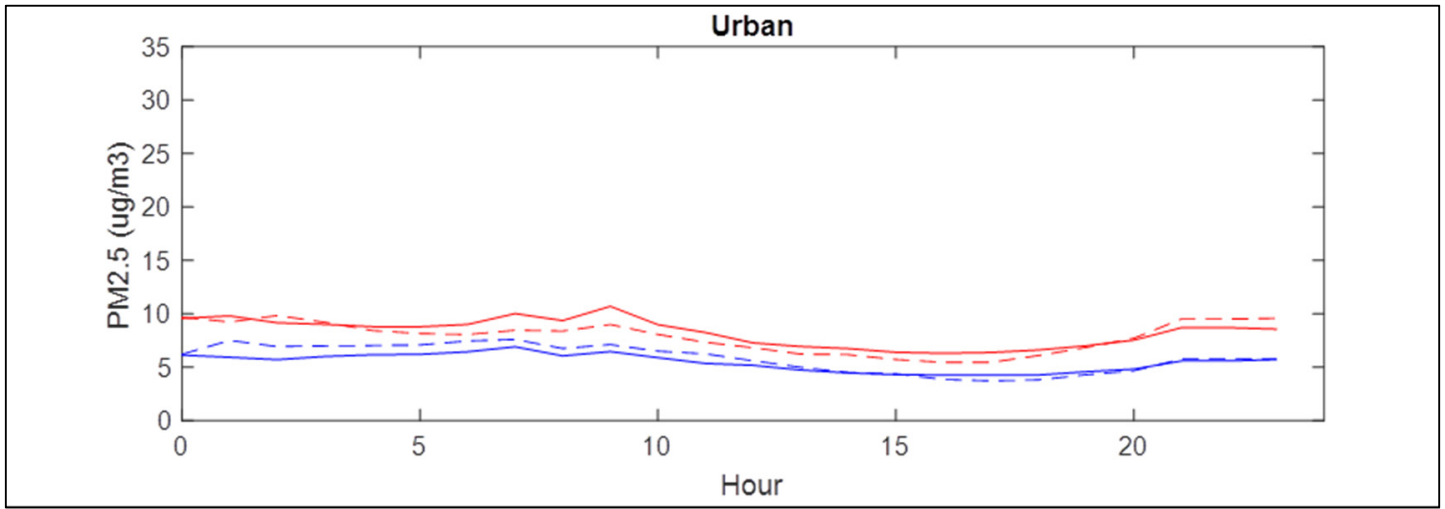

(b)

Figure 6. Hourly $\mathrm{PM}_{10}(\mathbf{a})$ and $\mathrm{PM}_{2.5}$ (b) concentration profile of working days and weekends for the reference and lockdown periods.

There was a reduction in particle concentrations during working days in 2020 compared to the reference period, being more noticeable for $\mathrm{PM}_{10}$. Average concentrations of $18.7 \mu \mathrm{g} \cdot \mathrm{m}^{-3}$ and $8.3 \mu \mathrm{g} \cdot \mathrm{m}^{-3}$ were found for $\mathrm{PM}_{10}$ and $\mathrm{PM}_{2.5}$, respectively, in 2020 and $8.9 \mu \mathrm{g} \cdot \mathrm{m}^{-3}$ and $5.5 \mu \mathrm{g} \cdot \mathrm{m}^{-3}$ during the reference period. A clear pattern in the working days of the reference period with an increase of $\mathrm{PM}_{10}$ was observed at 8:00 a.m., reaching 
$31.9 \mu \mathrm{g} \cdot \mathrm{m}^{-3}$, coinciding with citizens commuting to work. This is also slightly reflected in $\mathrm{PM}_{2.5}$ levels; hourly concentrations reached the highest values of $10.70 \mu \mathrm{g} \cdot \mathrm{m}^{-3}$ and $6.47 \mu \mathrm{g} \cdot \mathrm{m}^{-3}$ in the reference and lockdown periods, respectively. On weekends, the $\mathrm{PM}_{10}$ curve flattened and this peak dropped to $20.6 \mu \mathrm{g} \cdot \mathrm{m}^{-3}$. Nevertheless, during the lockdown, there was almost no distinction between the profiles of working days and weekends, explained by the stoppage of human activities and reduction of traffic. Although this effect was lower for $\mathrm{PM}_{2.5}$ at traffic stations, a reduction in hourly values and a smoothing of the profile with respect to the reference period were still observed but with insignificant differences between weekdays and weekend profiles. Ref. [44] identified numerous sources of PM in traffic-influenced urban environments, many of them non-vehicular and with different contribution of $\mathrm{PM}_{10}$ and $\mathrm{PM}_{2.5}$. This supports the observed differences between the reference and lockdown periods and the persistence of considerable levels of PM during lockdown despite drastically reduced activity of the main emission sources in this environment.

A moderate increase was also evident in the afternoon; the profile shows that the return from work is steeper and starts at 7:00 p.m. The augmentation of particle concentrations at the end of the day may be attributed to the traffic flows, emissions of the heating systems and a descent in the planetary boundary layer height, as observed in other studies [45], the latter being responsible for the levels observed during the first hours of the night. In 2020, a reduction of concentration was maintained during the whole day, although the first peak in the morning was lower and $\mathrm{PM}_{10}$ varied from $21.7 \mu \mathrm{g} \cdot \mathrm{m}^{-3}$ to $14.0 \mu \mathrm{g} \cdot \mathrm{m}^{-3}$, which is in agreement with a reduction in traffic intensity.

Regarding rural and suburban sites (Figures S6 and S7), $\mathrm{PM}_{10}$ concentrations on working days and weekends in 2020 were similar to the weekend profile and values during the reference period. Concentration peaks at the same time as occurred in urban cabins, although they were less perceptible, indicating that traffic emissions contributed to $\mathrm{PM}_{10}$ concentration for these AQCs. The hourly trends for rural and suburban sites showed similar $\mathrm{PM}_{2.5}$ concentrations and hourly patterns to urban cabins in 2020 for both working days and weekends, with negligible differences when comparing the reference and the lockdown periods. This is because the contribution of $\mathrm{PM}_{2.5}$ in these environments mainly occurs on a regional scale. Although anthropogenic mobility was drastically reduced, there were still emissions of secondary aerosol precursors from activities such as agriculture, farming, domestic heating and industry, which led to the formation and transport of $\mathrm{PM}_{2.5}$.

\subsection{Cluster Analysis}

The dendrogram combining the set of $\mathrm{PM}_{10}$ and $\mathrm{PM}_{2.5}$ concentrations of each AQC considering the whole period of study (2015 to 2020) and using as distance 1 minus the Pearson correlation coefficient resulted in clustering, as shown in Figure 7. To better explain the agglomerations of AQCs, we introduced the COA/INN attribute, which denotes its location in the coast or inland.

The first cluster includes most of the stations that were both BK and IND, even though there were cabins that pertain to all three provinces. A central cluster enclosing most of the AQCs that were both IND and COA is observed. It also includes ALM2 and BURR, which are URB/IND/COA and RUR/IND/COA, respectively. RABA and ALC2 are not in this cluster, but together in the third one. This may be because the first cluster is in Alicante, where industrial activity is not as intense as in Castellón, which is the province where most of the cabins in this cluster are located. Nevertheless, the reason why ALC2, which fulfills the characteristics of this cluster, has not been included here is unclear. The fourth cluster includes two out of the three traffic cabins, where traffic dominates the patterns of the PM data. POLI is included here as well and, although classified as SUB due to its location, is exposed to heavy traffic as it is on the way to the main university nuclei in Valencia and on the way to the beach zone. Further, the chosen separation of clusters excludes PIST from this cluster and gives rise to a new one consisting only of this station, which shares similarities with the aforementioned cluster. 


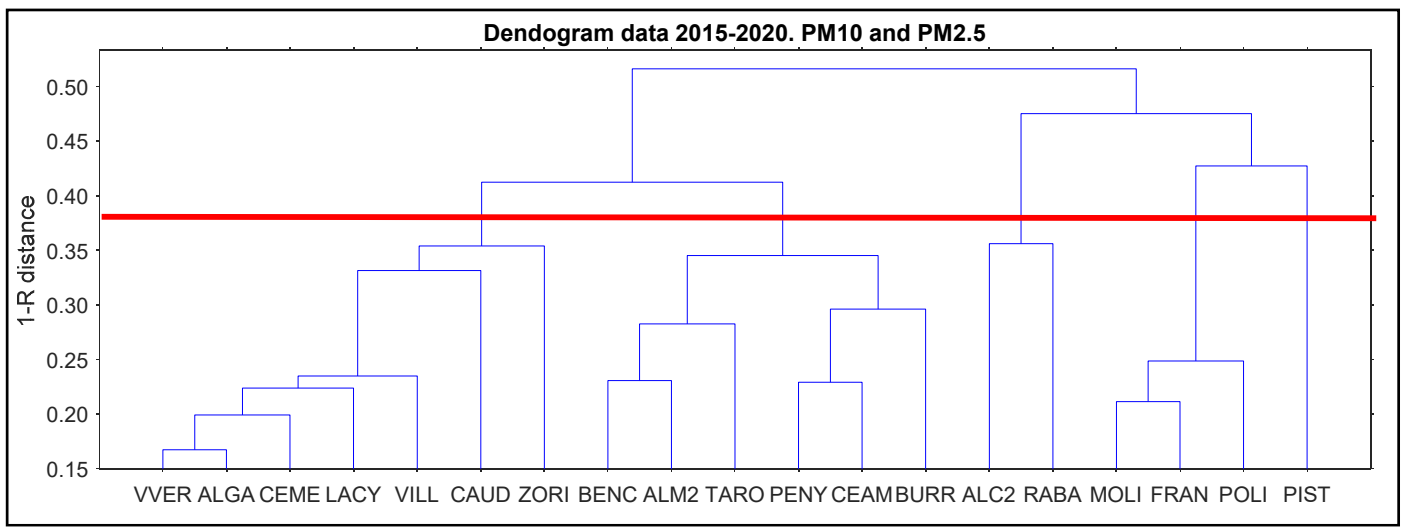

Figure 7. Dendrogram using 1-R (Pearson coefficient) as distance using $\mathrm{PM}_{10}$ and $\mathrm{PM}_{2.5}$ concentration data.

The application of non-supervised cluster analysis confirmed similarities between groups of AQCs according to the emissions to which they are exposed rather than to the environment type classification.

\subsection{Impact of Meteorological Parameters on PM}

Meteorological parameters govern the main natural sources of PM, with sinks being a key driving factor. For this reason, together with the effect of the intensity reduction of anthropogenic sources, an assessment of the relationship between meteorology and PM concentration evolution during the study period was completed. In the supplementary material, Table S6 provides summary statistics on the meteorological parameters of the 11 AQCs that reported data for both the reference and lockdown periods. Mean temperature and standard deviation values were very similar for all seasons in both periods. However, compared to the reference period, the study region was characterized by less radiation and higher values of precipitation and relative humidity during lockdown.

To assess the dependency of the PM concentration patterns with environmental parameters during the lockdown period and their possible role in the unexpected increase of PM observed in some AQCs, the correlation of PM with TEMP, RH, RF, RAD and WS was calculated along with the $p$-values (Tables S7 and S8). Although meteorological data were not collected for all the cabins, these are available for 11 out of the total of 19 AQCs considered in this study, including those cabins reporting a relative increase of particulate matter during the COVID-19 period. Radiation is a key factor in the formation of $\mathrm{PM}_{2.5}$. However, as mentioned above, there was, in general, less intense radiation in the study area during the lockdown compared to the reference period, leading to a nonsignificant correlation between RAD and $\mathrm{PM}_{2.5}$ at all of the stations analyzed. Nevertheless, a notable dependence between RH and WS for some of the cabins was found. As expected [30,46], there was a positive correlation between $\mathrm{RH}$ and $\mathrm{PM}$ concentration, explained by $\mathrm{RH}$ facilitating multiphase reactions that resulted in aerosol formation and growth [47]. In CEME, which showed increases of $30.3 \%$ and $44.8 \%$ in $\mathrm{PM}_{10}$ and $\mathrm{PM}_{2.5}$, respectively, $\mathrm{R}$ values of 0.59 and 0.50 were found in the regression of $\mathrm{PM}_{10}$ and $\mathrm{PM}_{2.5}$ concentrations, respectively, versus $\mathrm{RH}$. The same behavior was observed in CEAS, which experienced similar variations, with $R$ values of 0.41 and 0.48 for $\mathrm{PM}_{10}$ and $\mathrm{PM}_{2.5}$, respectively. Conversely, there was an anticorrelation with the wind speed, indicating that wind affects the cleanliness of the environment, as reported in other studies [30,46,48-50]. The higher the wind speed, the lower the concentration; therefore, PM levels were affected by the wind speed conditions, which could explain the increase of particulate matter during the lockdown period. In CEME, negative $\mathrm{R}$ values of 0.66 and 0.68 were found for $\mathrm{PM}_{10}$ and $\mathrm{PM}_{2.5}$, respectively. The same behavior was observed in CEAS, with negative values of 0.58 and 0.63 , and in VILL, where the values were 0.65 and 0.66 . In addition, the same pattern was observed in PENY, though with more moderated correlation coefficients. Nevertheless, the observed 
correlation with WS did not produce a rise in PM in ALM2. The combined effect of WS and RH may partly explain the unexpected PM increases found in some cabins. Regarding TARO, wind speed data were not collected, although an anticorrelation was found with PLU, which may partly explain its increase of $33.8 \%$ in $\mathrm{PM}_{2.5}$. Therefore, these calculations might explain the dependency of PM on environmental parameters, suggesting that the main factor was the meteorological dependence rather than the source type. A characterization of the particle composition would be needed to further explain the PM patterns found and elucidate to which extent meteorology played a role. In all the cases above mentioned, $p$-values were found to be below the threshold 0.05 , being therefore relevant for the correlations.

Figure S8a-c in the supplementary material illustrates anticorrelation of the PM concentrations with the wind speed, as well as pluviometry (Figure S8a,b, respectively) and correlation with RH (Figure S8c) during the lockdown. As can be clearly seen in Figure S8a, at the ALM station the concentration levels of $\mathrm{PM}_{10}$ and $\mathrm{PM}_{2.5}$ decreased as daily wind speed increased, reflecting efficient air renewal at wind speeds above $1 \mathrm{~m} \cdot \mathrm{s}^{-1}$. Figure $\mathrm{S} 8 \mathrm{~b}$ shows how effective wet deposition is as a sink for suspended particulate matter. It can be seen that on several occasions during the study period, precipitation led to a drastic decrease in the levels of $\mathrm{PM}_{10}$ and $\mathrm{PM}_{2.5}$ particles at TARO station. In Figure S8c, the correlation between PM and RH is easily observable at CEME station, reflecting a very similar evolution over the whole measurement period.

\subsection{VOCs Concentration Variation}

This section aims to analyze the overall variation and daily evolution of BTXs in the three urban traffic stations (PNAT, PIST and PLA) reporting these data during the lockdown. Average concentrations of benzene, toluene and xylene were lower during lockdown than in the 2015-2019 period. The lockdown period was characterized by a less dispersed database and by considerably lower hourly percentile 95 and absolute maximum values for every pollutant considered. As can be seen in Figure 8, for the set of stations, the general variation in BTX levels was notable; levels of benzene, toluene and xylene decreased by $77.4 \%, 58.0 \%$ and $61.8 \%$, respectively, in 2015-2019. Ref. [50] reported a similar percentage drop $(67 \%)$ in VOC levels from traffic during lockdown in China. Analyzing the stations individually, the greatest reduction in BTX levels was recorded at the PLA station (Alicante), accounting for a percentage concentration reduction of $86.0 \%, 87.1 \%$ and $90.8 \%$ in benzene, toluene and xylene, respectively, in the lockdown period compared to the reference period. However, there were also strong variations in each VOC measured for the other stations. Benzene and xylene concentrations recorded average decreases of up to $78.5 \%$ and $49.4 \%$ in PNAT (Castellón), while toluene recorded an average decrease of up to $49.2 \%$ at PIST station (Valencia). The latter figure is in agreement with $\mathrm{PM}_{10}$ and $\mathrm{PM}_{2.5}$ reductions found in this site as a result of the mobility restrictions that resulted in a traffic drop. Therefore, apart from a decrease in primary particle emissions due to lower traffic flow, it is expected that this reduction in BTX levels has contributed to the decline found in $\mathrm{PM}_{2.5}$ levels by limiting the further photooxidative production of SOA.

Figure $9 \mathrm{a}-\mathrm{c}$ shows the daily evolution of VOCs at the different stations. Benzene showed a clear decrease in its daily concentrations in all stations throughout the period, only showing slight increases at the end of the lockdown period with respect to the reference period at the PNAT station. Although the same trend can be observed at the PLA station for toluene and xylene, leading to the large overall percentage decreases previously highlighted, it can also be seen that there have been non-negligible emissions at the other stations (PIST and PNAT), resulting in similar and even higher daily concentrations than in the reference period for some days. While particles can be both primary and secondary pollutants, at these stations, BTXs are mainly primary, being largely contributed by vehicle exhaust. This explains the higher variations in BTX than in PM, the latter being softened by other emission sources and processes, as stated above. 


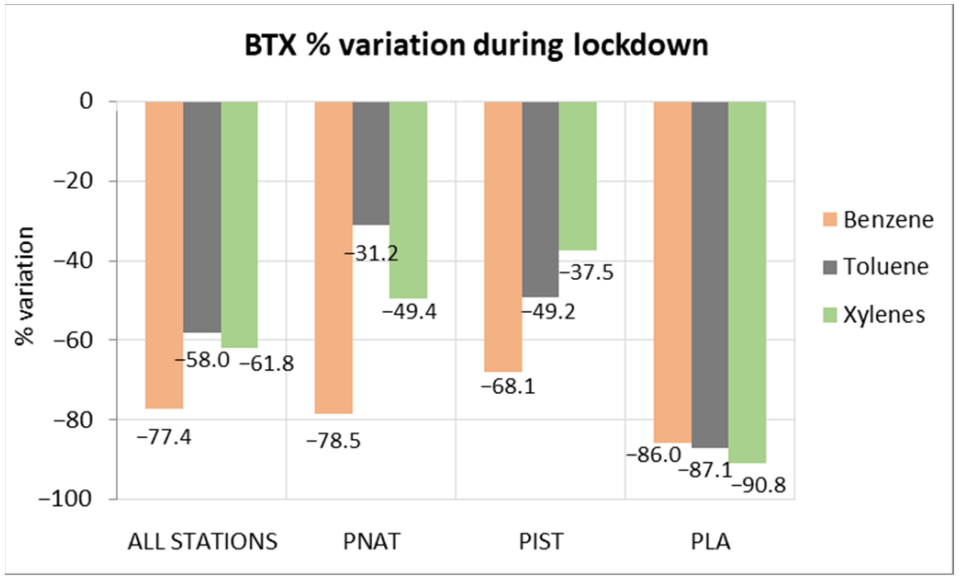

Figure 8. \% Variation of BTX for all stations considered.

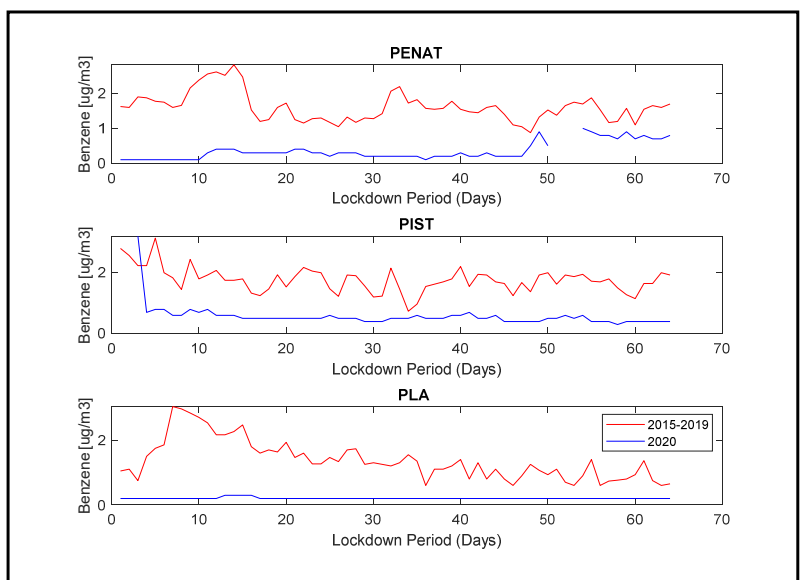

(a)
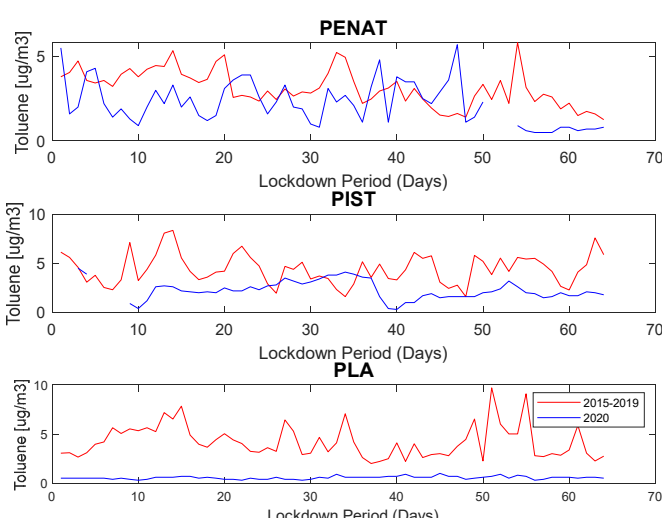

(b)
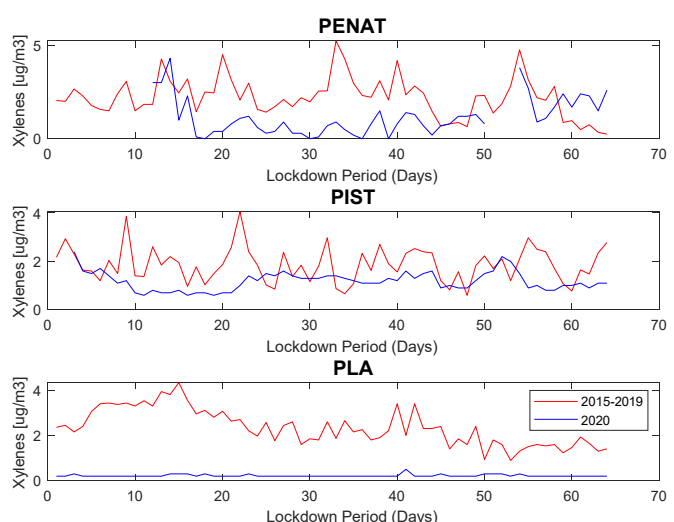

(c)

Figure 9. (a) Benzene (b) toluene and (c) xylene daily evolution at different stations during lockdown and reference period. Values expressed in $\mu \mathrm{g} \cdot \mathrm{m}^{-3}$.

\section{Conclusions}

The COVID-19 pandemic led to an unprecedented reduction of anthropogenic activity. This work evaluated the variation of $\mathrm{PM}_{10}, \mathrm{PM}_{2.5}$ and $\mathrm{BTX}$ concentrations due to the COVID-19 lockdown. Unlike most of the studies in which AQCs in cities have been considered, this work presents a study of the behavior of PM concentrations considering a network of AQCs within a whole region, i.e., enclosing cabins exposed to different 
emissions (traffic, industrial, background), in different environments (urban, suburban, rural) and locations (coast, inner). A thorough statistical analysis of PM was carried out.

Despite a halt in human activity, PM concentrations did not follow the expected behavior in this lockdown. $\mathrm{PM}_{10}$ concentrations showed an overall percentage reduction of $16.5 \%$ in 2020 while $\mathrm{PM}_{2.5}$ levels increased by $3.1 \%$. This period also showed lower variability of concentrations than the reference as observed in the box plots. Nonsupervised cluster analysis confirmed that the main similarities in concentration trends in different AQCs respond to the type of emissions they are exposed to. Urban and rural areas recorded a reduction in $\mathrm{PM}_{10}$ and $\mathrm{PM}_{2.5}$ levels, while suburban areas experienced an increase in both PM fractions. As expected, AQCs labelled as urban and exposed to traffic emissions experienced the most drastic reductions, while in industrial areas the reductions were more moderate for $\mathrm{PM}_{10}$, and an increase for $\mathrm{PM}_{2.5}$ was observed. The increase of the $\mathrm{PM}$ concentration in some AQCs during the period studied in 2020 may, in part, be explained by meteorological parameters, as a dependency has been found between PM and wind speed, relative humidity and rainfall. Exhaustive statistical analysis has been carried out by applying blind clusters to explore the behavior of the AQC network, confirming similar performance in groups of cabins classified by their features.

Our study confirms that the stoppage of anthropogenic activities during the lockdown has also affected the hourly pattern of particle concentration. In general, it has flattened the profile and reduced the average values, especially in rural and traffic AQCs.

Reduction of the activity during the COVID-19 lockdown resulted in a diminution of contaminants as observed in many observational and model studies worldwide. In this study, we have found substantial drops in benzene, toluene and xylene by $77.4 \%, 58.0 \%$ and $61.8 \%$, respectively. As stated above, for emission sources other than traffic, particles can be both primary and secondary pollutants, e.g., heating systems and dispersed emissions from surrounding industrial or farming areas. The chemistry of PM is non-linear and complex, and the oxidative capacity of the atmosphere might have increased due to enhanced ozone concentration resulting from less NO titration, leading to an increase of secondary aerosols. This, together with meteorological aspects, might have compensated for and lessened the overall reduction of aerosols.

Even though this lockdown allowed us to analyze a unique scenario, the brevity of this period of study calls for the further characterization of the worldwide impact of the reduction in anthropogenic activity on PM and other pollutants' concentrations. Accordingly, more research on PM chemical composition and emission sources is needed to fully understand and explain the impact of lockdown on PM concentration and size distribution. Our study supports the idea that the control of the air quality, especially of particulate pollution, has to be evaluated considering different factors: emission sources, secondary formation, effective oxidizing capacity of the atmosphere and meteorology.

The evaluation period has been a unique opportunity, and our study, by including coverage of different scenarios and a thorough statistical analysis, presents valuable information on the effect of the reduction and halt of anthropogenic activities over a network of AQCs comprising different environments and affected by different types of emission sources. Our findings may help to establish a basis for future scientific air pollution control strategies and for improving air quality policies to counteract air pollution and to place human health at the center of urban planning.

Supplementary Materials: The following supporting information can be downloaded at: https: / / www.mdpi.com/article/10.3390/atmos13010097/s1, Table S1. Summary of AQCs considered in this work and environmental and pollutant data reported; Table S2: Statistics of $\mathrm{PM}_{10}$ data set of each air quality cabin during reference and lockdown periods and their percentage variation; Table S3: Statistics of $\mathrm{PM}_{2.5}$ data set of each air quality cabin during reference and lockdown periods and their percentage variation; Table S4: Overall mean, standard deviation (Sd), median, 5th and 95th percentiles (P05 and P95), minimum (Min) and maximum (Max) values for $\mathrm{PM}_{10}, \mathrm{PM}_{2.5}$ and BTX for reference and lockdown periods considering all AQCs in this study; Table S5: Mean PM concentrations and standard deviations for all air quality cabins grouped by type of environment and emission 
for both periods of study and PM percentage variation during lockdown compared to the reference period; Table S6: Statistical summary of environmental parameters of each air quality cabin during reference and lockdown periods; Table S7: Pearson's correlation coefficient, R, between $\mathrm{PM}_{10}$ and $\mathrm{PM}_{2.5}$ and meteorological variables; Table S8: $p$-values between $\mathrm{PM}_{10}$ and $\mathrm{PM}_{2.5}$ and meteorological variables; Figure S1. Box plot of (a) $\mathrm{PM}_{10}$ and (b) $\mathrm{PM}_{2.5}$ concentration in the AQCs for reference and lockdown periods; Figure S2. (a,b) Box plots by environment type. (a,b) represent $\mathrm{PM}_{10}$ and $\mathrm{PM}_{2.5}$ respectively in the reference, sorted by year, and the lockdown periods; Figure S3. (a,b) Box plots by emission type. $(\mathbf{a}, \mathbf{b})$ represent $\mathrm{PM}_{10}$ and $\mathrm{PM}_{2.5}$ respectively in the reference, sorted by year, and the lockdown periods. Figure S4: Hourly $\mathrm{PM}_{2.5}$ profile comparing reference and lockdown periods; Figure S5: Hourly $\mathrm{PM}_{10}$ profile comparing reference and lockdown periods; Figure S6: Hourly $\mathrm{PM}_{10}$ concentration profile by environment type for reference and lockdown periods; Figure S7: Hourly $\mathrm{PM}_{2.5}$ concentration profile by environment type for reference and lockdown periods; Figure S8. PM and meteorological variables time series to illustrate anticorrelation in (a) ALM and (b) TARO and correlation in (c) CEME stations during lockdown.

Author Contributions: Conceptualization, M.R., R.S., E.B., T.V., J.J.D. and A.M.; Methodology, M.R., R.S., E.B., T.V., J.J.D. and A.M.; Data curation, M.R. and R.S.; Formal analysis, M.R. and R.S.; Data resources: J.J.D.; Investigation, M.R. and R.S.; Writing—original draft, M.R. and R.S.; Validation, E.B.; Writing-review \& editing, M.R., R.S., E.B., T.V. and A.M.; Supervision, A.M. All authors have read and agreed to the published version of the manuscript.

Funding: This work was supported by the projects CAPOX (RTI2018-097768-B-C21, Spanish Ministry of Science, Innovation and Universities) and IMAGINA_PROMETEO (PROMETEO/2019/110, Generalitat Valenciana).

Data Availability Statement: Data presented in this study are available at the webpage of the AQ Network of the Generalitat Valenciana. (http://agroambient.gva.es/es/web/calidad-ambiental/ datos-historicos). Last access date: 29 December 2021.

Acknowledgments: Fundación CEAM is partly supported by the Generalitat Valenciana, by the IMAGINA_PROMETEO (PROMETEO/2019/110) project and by the CAPOX project (RTI2018-097768-B-C21).

Conflicts of Interest: The authors declare no conflict of interest.

\section{References}

1. Chen, R.; Kan, H.; Chen, B.; Huang, W.; Bai, Z.; Song, G.; Pan, G. Association of Particulate Air Pollution with Daily Mortality. Am. J. Epidemiol. 2012, 175, 1173-1181. [CrossRef] [PubMed]

2. Chen, C.-H.; Wu, C.-D.; Chiang, H.-C.; Chu, D.; Lee, K.-Y.; Lin, W.-Y.; Yeh, J.-I.; Tsai, K.-W.; Guo, Y.L. The effects of fine and coarse particulate matter on lung function among the elderly. Sci. Rep. 2019, 9, 14790. [CrossRef]

3. Dockery, D.W.; Stone, P.H. Cardiovascular Risks from Fine Particulate Air Pollution. N. Engl. J. Med. 2007, 356, 511-513. [CrossRef]

4. Miller, K.A.; Siscovick, D.S.; Sheppard, L.; Shepherd, K.; Sullivan, J.H.; Anderson, G.L.; Kaufman, J.D. Long-Term Exposure to Air Pollution and Incidence of Cardiovascular Events in Women. N. Engl. J. Med. 2007, 356, 447-458. [CrossRef]

5. World Health Organization. Ambient (Outdoor) Air Pollution. 2018. Available online: https://www.who.int/news-room/factsheets / detail/ambient-(outdoor)-air-quality-and-health (accessed on 4 December 2021).

6. European Environment Agency. Excedance Of Air Quality Standards in Europe. 2021. Available online: https://www.eea.europa. eu/ims / exceedance-of-air-quality-standards (accessed on 4 December 2021).

7. Querol, X.; Alastuey, A.; Rodriguez, S.; Plana, F.; Ruiz, C.; Cots, N.; Massagué, G.; Puig, O. PM 10 and PM 2.5 source apportionment in the Barcelona Metropolitan Area, Catalonia, Spain. Atmos. Environ. 2001, 35, 6407-6419. [CrossRef]

8. Viana, M.; Kuhlbusch, T.A.J.; Querol, X.; Alastuey, A.; Harrison, R.M.; Hopke, P.K.; Winiwarter, W.; Vallius, M.; Szidat, S.; Prévôt, A.S.H.; et al. Source apportionment of particulate matter in Europe: A review of methods and results. J. Aerosol Sci. 2008, 39, 827-849. [CrossRef]

9. Schnatter, A.R.; Glass, D.; Tang, G.; Irons, R.D.; Rushton, L. Myelodysplastic Syndrome and Benzene Exposure Among Petroleum Workers: An International Pooled Analysis. J. Natl. Cancer Inst. 2012, 104, 1724-1737. [CrossRef]

10. Masih, A.; Anurag, L.; Taneja, A.; Singhvi, R. Inhalation exposure and related health risks of BTEX in ambient air at different microenvironments of a terai zone in north India. Atmos. Environ. 2016, 147, 55-66. [CrossRef]

11. Carter, W.P.L. Development of Ozone Reactivity Scales for Volatile Organic Compounds. Air Waste 1994, 44, 881-899. [CrossRef]

12. Seinfeld, J.H.; Pandis, S.N. Atmospheric Chemistry and Physics: From Air Pollution to Climate Change; John Wiley \& Sons: Hoboken, NJ, USA, 2006.

13. Henze, D.K.; Seinfeld, J.H.; Ng, N.L.; Kroll, J.H.; Fu, T.-M.; Jacob, D.J.; Heald, C.L. Global modeling of secondary organic aerosol formation from aromatic hydrocarbons: High- vs. low-yield pathways. Atmos. Chem. Phys. Discuss. 2008, 8, 2405-2420. [CrossRef] 
14. Kerchich, Y.; Kerbachi, R. Measurement of BTEX (benzene, toluene, ethybenzene, and xylene) levels at urban and semirural areas of Algiers City using passive air samplers. J. Air Waste Manag. Assoc. 2012, 62, 1370-1379. [CrossRef] [PubMed]

15. Buczynska, A.J.; Krata, A.; Stranger, M.; Godoi, A.F.L.; Kontozova-Deutsch, V.; Bencs, L.; Naveau, I.; Roekens, E.; Van Grieken, R. Atmospheric BTEX-concentrations in an area with intensive street traffic. Atmos. Environ. 2009, 43, 311-318. [CrossRef]

16. Our World in Data. Coronavirus Disease (COVID-19)—Statistics and Research. Oxford Martin School. Oxon. Global Change Data Lab. 2021. Available online: https:/ / ourworldindata.org/coronavirus/ (accessed on 31 November 2021).

17. Rodríguez-Urrego, D.; Rodríguez-Urrego, L. Air quality during the COVID-19: PM2.5 analysis in the 50 most polluted capital cities in the world. Environ. Pollut. 2020, 266, 115042. [CrossRef] [PubMed]

18. Yin, Z.; Zhang, Y.; Wang, H.; Li, Y. Evident PM2.5 drops in the east of China due to the COVID-19 quarantine measures in February. Atmos. Chem. Phys. Discuss. 2021, 21, 1581-1592. [CrossRef]

19. Le, T.; Wang, Y.; Liu, L.; Yang, J.; Yung, Y.L.; Li, G.; Seinfeld, J.H. Unexpected air pollution with marked emission reductions during the COVID-19 outbreak in China. Science 2020, 369, 702-706. [CrossRef] [PubMed]

20. Zhang, F.; Wang, Y.; Peng, J.; Chen, L.; Sun, Y.; Duan, L.; Ge, X.; Li, Y.; Zhao, J.; Liu, C.; et al. An unexpected catalyst dominates formation and radiative forcing of regional haze. Proc. Natl. Acad. Sci. USA 2020, 117, 3960-3966. [CrossRef] [PubMed]

21. Mao, L.; Liu, R.; Liao, W.; Wang, X.; Shao, M.; Liu, S.C.; Zhang, Y. An observation-based perspective of winter haze days in four major polluted regions of China. Natl. Sci. Rev. 2019, 6, 515-523. [CrossRef] [PubMed]

22. Shen, J.; Bigi, A.; Marinoni, A.; Lampilahti, J.; Kontkanen, J.; Ciarelli, G.; Putaud, J.P.; Nieminen, T.; Kulmala, M.; Lehtipalo, K.; et al. Emerging Investigator Series: COVID-19 lockdown effects on aerosol particle size distributions in northern Italy. Environ. Sci. Atmos. 2021, 1, 214-227. [CrossRef] [PubMed]

23. Ciarelli, G.; Jiang, J.; El Haddad, I.; Bigi, A.; Aksoyoglu, S.; Prévôt, A.S.H.; Marinoni, A.; Shen, J.; Yan, C.; Bianchi, F. Modeling the effect of reduced traffic due to COVID-19 measures on air quality using a chemical transport model: Impacts on the Po Valley and the Swiss Plateau regions. Environ. Sci. Atmos. 2021, 1, 228-240. [CrossRef] [PubMed]

24. Sicard, P.; De Marco, A.; Agathokleous, E.; Feng, Z.; Xu, X.; Paoletti, E.; Rodriguez, J.J.D.; Calatayud, V. Amplified ozone pollution in cities during the COVID-19 lockdown. Sci. Total Environ. 2020, 735, 139542. [CrossRef] [PubMed]

25. Briz-Redón, Á.; Belenguer-Sapiña, C.; Serrano-Aroca, Á. Changes in air pollution during COVID-19 lockdown in Spain: A multicity study. J. Environ. Sci. 2021, 101, 16-26. [CrossRef]

26. Tobías, A.; Carnerero, C.; Reche, C.; Massagué, J.; Via, M.; Minguillón, M.C.; Alastuey, A.; Querol, X. Changes in air quality during the lockdown in Barcelona (Spain) one month into the SARS-CoV-2 epidemic. Sci. Total Environ. 2020, 726, 138540. [CrossRef] [PubMed]

27. Parker, H.A.; Hasheminassab, S.; Crounse, J.D.; Roehl, C.M.; Wennberg, P.O. Impacts of Traffic Reductions Associated with COVID-19 on Southern California Air Quality. Geophys. Res. Lett. 2020, 47, e2020GL090164. [CrossRef]

28. Ogen, Y. Assessing nitrogen dioxide (NO2) levels as a contributing factor to the coronavirus (COVID-19) fatality rate. Sci. Total Environ. 2020, 726, 138605. [CrossRef]

29. Fuzzi, S.; Baltensperger, U.; Carslaw, K.; Decesari, S.; Van Der Gon, H.D.; Facchini, M.C.; Fowler, D.; Koren, I.; Langford, B.; Lohmann, U.; et al. Particulate matter, air quality and climate: Lessons learned and future needs. Atmos. Chem. Phys. Discuss. 2015, 15, 8217-8299. [CrossRef]

30. Jacob, D.J.; Winner, D.A. Effect of climate change on air quality. Atmos. Environ. 2009, 43, 51-63. [CrossRef]

31. Petetin, H.; Bowdalo, D.; Soret, A.; Guevara, M.; Jorba, O.; Serradell, K.; García-Pando, C.P. Meteorology-normalized impact of the COVID-19 lockdown upon $\mathrm{NO}_{2}$ pollution in Spain. Atmos. Chem. Phys. Discuss. 2020, 20, 11119-11141. [CrossRef]

32. Spanish Ministry Miteco Website. 2021. Available online: https:/ / www.miteco.gob.es/ (accessed on 4 December 2021).

33. Draxler, R.R.; Rolph, G.D. HYSPLIT., Model Access Via NOAA ARL READY Website. 2015. Available online: http:/ / ready.arl. noaa.gov/HYSPLIT.php (accessed on 30 October 2012).

34. Stein, A.F.; Draxler, R.R.; Rolph, G.D.; Stunder, B.J.B.; Cohen, M.D.; Ngan, F. NOAA's HYSPLIT Atmospheric Transport and Dispersion Modeling System. Bull. Am. Meteorol. Soc. 2015, 96, 2059-2077. [CrossRef]

35. Querol, X.; Alastuey, A.; Pey, J.; Escudero, M.; Castillo, S.; Gonzalez, A.; Pallares, M.; Jiménez, S.; Cristobal, A.; Ferreira, F.; et al. Spain and Portugal Methodology for the identification of natural African dust episodes in PM10 and PM2.5, and justification with regards to the exceedances of the PM10 daily limit value. Environ. Sci. Pollut. Res. 2006, 35, 1151-1172.

36. Sarkar, M.; Das, A.; Mukhopadhyay, S. Assessing the immediate impact of COVID-19 lockdown on the air quality of Kolkata and Howrah, West Bengal, India. Environ. Dev. Sustain. 2021, 23, 8613-8642. [CrossRef]

37. Núñez, D.; Pérez, L.V.; Manzoor, S.; Cáceres, J.O. Statistical Tools for Air Pollution Assessment: Multivariate and Spatial Analysis Studies in the Madrid Region. J. Anal. Methods Chem. 2019, 2019, 975392.

38. Matlab. Statistics and Machine Learning Toolbox ${ }^{\mathrm{TM}}$, Version 2019a; The MathWorks, Inc.: Natick, MA, USA, 2019.

39. Morel, P. Gramm: Grammar of graphics plotting in Matlab. J. Open Source Softw. 2018, 3, 23-568. [CrossRef]

40. Donzelli, G.; Cioni, L.; Cancellieri, M.; Llopis-Morales, A.; Morales-Suárez-Varela, M. Relations between Air Quality and COVID-19 Lockdown Measures in Valencia, Spain. Int. J. Environ. Res. Public Health 2021, 18, 2296. [CrossRef]

41. Wyche, K.; Nichols, M.; Parfitt, H.; Beckett, P.; Gregg, D.; Smallbone, K.; Monks, P. Changes in ambient air quality and atmospheric composition and reactivity in the South East of the UK as a result of the COVID-19 lockdown. Sci. Total Environ. 2021, 755, 142526. [CrossRef] [PubMed] 
42. Querol, X.; Massagué, J.; Alastuey, A.; Moreno, T.; Gangoiti, G.; Mantilla, E.; Diéguez, J.J.; Escudero, M.; Monfort, E.; Pérez García-Pando, C.; et al. Lessons from the COVID-19 air pollution decrease in Spain: Now what? Sci. Total Environ. 2021, 779, 146380. [CrossRef]

43. Menut, L.; Bessagnet, B.; Siour, G.; Mailler, S.; Pennel, R.; Cholakian, A. Impact of lockdown measures to combat COVID-19 on air quality over western Europe. Sci. Total Environ. 2020, 741, 140426. [CrossRef]

44. Pio, C.; Alves, C.; Nunes, T.; Cerqueira, M.; Lucarelli, F.; Nava, S.; Calzolai, G.; Gianelle, V.; Colombi, C.; Amato, F.; et al. Source apportionment of $\mathrm{PM}_{2.5}$ and $\mathrm{PM}_{10}$ by Ionic and Mass Balance (IMB) in a traffic-influenced urban atmosphere, in Portugal. Atmos. Environ. 2020, 223, 117217. [CrossRef]

45. Salvador, P.; Pandolfi, M.; Tobías, A.; Gómez-Moreno, F.J.; Molero, F.; Barreiro, M.; Pérez, N.; Revuelta, M.A.; Marco, I.M.; Querol, X.; et al. Impact of mixing layer height variations on air pollutant concentrations and health in a European urban area: Madrid (Spain), a case study. Environ. Sci. Pollut. Res. 2020, 27, 41702-41716. [CrossRef]

46. Xu, Y.; Xue, W.; Lei, Y.; Zhao, Y.; Cheng, S.; Ren, Z.; Huang, Q. Impact of Meteorological Conditions on PM 2.5 Pollution in China during Winter. Atmosphere 2018, 9, 429. [CrossRef]

47. Tie, X.; Huang, R.-J.; Cao, J.; Zhang, Q.; Cheng, Y.; Su, H.; Chang, D.; Pöschl, U.; Hoffmann, T.; Dusek, U.; et al. Severe Pollution in China Amplified by Atmospheric Moisture. Sci. Rep. 2017, 7, 15760. [CrossRef] [PubMed]

48. Keary, J.; Jennings, S.G.; O'Connor, T.C.; McManus, B.; Lee, M. PM10 Concentration Measurements in Dublin City. Environ. Monit. Assess. 1998, 52, 3-18. [CrossRef]

49. Galindo, N.; Varea, M.; Gil-Moltó, J.; Yubero, E.; Nicolás, J. The Influence of Meteorology on Particulate Matter Concentrations at an Urban Mediterranean Location. Water Air Soil Pollut. 2010, 215, 365-372. [CrossRef]

50. Wang, J. Impact of COVID-19 lockdown on ambient levels and sources of volatile organic compounds (VOCs) in Nanjing, China. Sci. Total Environ. 2021, 757, 143823. [CrossRef] [PubMed] 